\title{
Transient production of F-region irregularities associated with TCV passage
}

\author{
R. Kataoka ${ }^{1}$, H. Fukunishi ${ }^{1}$, K. Hosokawa ${ }^{2}$, H. Fujiwara ${ }^{1}$, A. S. Yukimatu ${ }^{3}$, N. Sato ${ }^{3}$, and Y.-K. Tung ${ }^{4}$ \\ ${ }^{1}$ Department of Geophysics, Tohoku University, 980-8578, Japan \\ ${ }^{2}$ Department of Geophysics, Kyoto University, 606-8502, Japan \\ ${ }^{3}$ National Institute of Polar Research, 173-8515, Japan \\ ${ }^{4}$ Space Sciences Laboratory, University of California, Berkeley, CA 94720-7450, USA
}

Received: 24 September 2002 - Revised: 25 December 2002 - Accepted: 28 February 2003

\begin{abstract}
Transient production of F-region plasma irregularities due to traveling convection vortices (TCVs) was investigated using the Super Dual Auroral Radar Network (SuperDARN) combined with ground magnetometer networks and the POLAR ultraviolet imager. We selected two largeamplitude (100-200 nT) TCV events that occurred on 22 May 1996 and 24 July 1996. It is found that the TCVassociated HF backscatter arises in blobs with spatial scale of a few hundreds $\mathrm{km}$. They traveled following tailward bulk motion of the TCV across the three fields-of-view of the SuperDARN HF radars in the prenoon sector. The spectra in the blobs showed unidirectional Doppler velocities of typically $400-600 \mathrm{~m} / \mathrm{s}$, with flow directions away from the radar. These unidirectional velocities correspond to the poleward and/or eastward convective flow near the leading edge of upward field-aligned current. The backscatter blobs overlapped the poleward and westward part of the TCV-related transient aurora. It is likely that the transient backscatter blobs are produced by the three-dimensional gradient drift instabilities in the three-dimensional current system of the TCV. In this case, nonlinear rapid evolution of irregularities would occur in the upward field-aligned current region. The spectral width of the backscatter blob is typically distributed between 50 and $300 \mathrm{~m} / \mathrm{s}$, but sometimes it is over $400 \mathrm{~m} / \mathrm{s}$. This suggests that the temporal broad spectra over $400 \mathrm{~m} / \mathrm{s}$ are produced by Pc1-2 bursts, while the background spectral width of $50-300 \mathrm{~m} / \mathrm{s}$ are produced by the velocity gradient structure of convection vortices themselves.
\end{abstract}

Key words. Ionosphere (Electric fields and currents; Ionospheric irregularities; Plasma convection)

\section{Introduction}

Ground-based magnetometers have observed the signatures of traveling convection vortices (TCVs) (e.g. Friis-

Correspondence to: R. Kataoka

(ryuho@pat.geophys.tohoku.ac.jp)
Christensen et al., 1988; Glassmeier and Heppner, 1992). These vortices correspond to spatially localized and transient convection cells embedded in a large-scale convection pattern. The vortices are accompanied by enhanced electric fields, particle precipitation, and pairs of upward/downward field-aligned currents. They are typically observed in the prenoon sector in geomagnetic high-latitudes between $70^{\circ}$ and $80^{\circ}$, and are aligned predominantly in the east-west direction. The longitudinal extent of each vortex structure ranges from 500 to $1500 \mathrm{~km}$ and its latitudinal extent is about $500 \mathrm{~km}$. Once formed, the vortex structures propagate tailward at speeds of several $\mathrm{km} / \mathrm{s}$, but they decay as they propagate with a lifetime of about $10-20 \mathrm{~min}$.

The transient response of the ionosphere to TCVs has been investigated by Schunk et al. $(1994,1998)$ using the ionospheric model of Utah State University. They showed that the ionospheric response includes localized temperature enhancements and ion composition changes, forming a structure of $\mathrm{O}^{+}$density depletion in the vortex wake at F-region altitude. The modeled "TCV wake" structure is consistent with some observations of incoherent scatter radars. Lühr et al. (1993) showed that rapid enhancements of ionospheric plasma drift and ion temperature were simultaneously observed during a TCV event. Also, Lühr et al. (1993, 1996) indicated that the Hall conductivity decreased in the upward field-aligned current region of a TCV. Valladares et al. (1999) showed that a section of the high-latitude plasma density was eroded by a factor of 2 during a TCV event, producing magnetic perturbations larger than $100 \mathrm{nT}$. Several investigations of TCV events were carried out using the Super Dual Auroral Radar Network (SuperDARN) measurements. Convection velocities of TCVs obtained by magnetometer networks and SuperDARN were found to be consistent (Lyatsky et al., 1999; Valladares et al., 1999; Kataoka et al., 2001). Kataoka et al. (2001) also found that SuperDARN data show a pronounced increase in the backscatter power and the Doppler spectral width as the TCV passes through the irregularity region.

We selected two TCV events which occurred on 22 May 
and 24 July 1996. The purpose of this paper is to investigate the ionospheric response of these TCV events, focusing on the transient production of F-region plasma irregularities. We took advantage of a horizontally wide coverage of the SuperDARN, ground magnetometer networks, and the POLAR ultraviolet imager (UVI). The basic characteristics of the transient irregularities themselves are also investigated in detail, focusing on the spectral width of backscatter echoes observed by the SuperDARN.

\section{Data set}

\subsection{SuperDARN}

The SuperDARN coherent HF radars are designed to employ backscatter from high-latitude field-aligned ionospheric plasma density irregularities as tracers of bulk plasma motion under the influence of the convection electric field (Greenwald et al., 1985, 1995). A number of authors demonstrated that the equatorward edge of the radar backscatter region showing broad $(>220 \mathrm{~m} / \mathrm{s})$ Doppler spectral widths is coincident with the equatorward edge of the cusp particle precipitation and red line aurora region (Baker et al., 1995; Rodger et al., 1995; Yeoman et al., 1997; Milan et al., 1999). Their results allow us to employ the low-latitude edge of the broad spectral width region as a proxy for the open/closed field line boundary at the ionospheric altitudes. This has been a great advantage in monitoring the interaction between the solar wind and the magnetosphere-ionosphere coupled system. Three HF radars at Saskatoon, Kapuskasing, and Goose Bay in the Northern Hemisphere were used to observe transient backscatter regions during the intervals of selected TCV events. Each radar can be operated at specific frequencies within the range from 8 to $20 \mathrm{MHz}$, although the operating frequency is typically near $10 \mathrm{MHz}$, which corresponds to a wavelength of the scattering plasma irregularities of $15 \mathrm{~m}$. During both events selected for this study, the radars were running in normal scan mode. The radar scans through 16 azimuthal beams every two minutes and the dwell time on each beam is typically $7 \mathrm{~s}$. Each beam is separated into 75 range gates, $45 \mathrm{~km}$ in length with a distance to the first gate of $180 \mathrm{~km}$.

\subsection{Magnetometer network}

We derive equivalent convection patterns in the Northern Hemisphere from ground magnetometer data using the identical method of Kataoka et al. (2001). This method performs high-pass filtering of magnetometer data with a 30-min frequency cutoff to extract the signal of interest, and then geomagnetic vectors in the horizontal plane are rotated by $90^{\circ}$ to provide the convection directions assuming Fukushima's theorem (Fukushima, 1969). Available magnetometer networks covering the TCV area are the Magnetometer Array for Cusp and Cleft Studies (MACCS) in Canada (Hughes and Engebretson, 1997), the Canadian Auroral Network for the OPEN Program Unified Study (CANOPUS) sites, and Greenland coastal and ice cap stations. Table 1 shows the locations and the names of the magnetometer stations used.

\subsection{POLAR UVI}

In order to investigate the effect of electron precipitation in a global view, we investigated the image data from the UVI instrument aboard the POLAR spacecraft (Torr et al., 1995). The UVI has five filters with different wavelength bands. The band used for this study is the Lyman-Birge-Hopfield long (LBHl) band in the range of $160-180 \mathrm{~nm}$. The auroral brightness from the LBHl band depends mainly on the total precipitating energy flux over a wide range of precipitating electron energy (Germany et al., 1994). All images shown are integrated for $36.8 \mathrm{~s}$. A line-of-sight correction, cosmic ray removal, and dayglow removal are also performed (see Chua, 2002).

\section{Observations}

We selected two large-amplitude (100-200 nT) TCV events that occurred on 22 May 1996 and 24 July 1996, respectively in the prenoon sector under quiet geomagnetic activity conditions. The northern polar region was sunlit because these events occurred near summer solstice. The time evolution of the current systems of the TCV events on 22 May and 24 July have been described by Kataoaka et al. (2002) and Sitar et al. (1998), respectively. The solar wind origins of the 22 May and 24 July TCV events were identified as interplanetary tangential discontinuities by Kataoka et al. (2002) and Sibeck et al. (1999), respectively.

The equivalent convection velocities derived from magnetometer data are shown by arrows in Figs. 1 and 2 for the 22 May and 24 July events, respectively. Superposed color maps in the left panels are UV auroral images obtained by POLARUVI. The color-coded map of Doppler velocity is superposed in the right panels. Positive (negative) values represent irregularity towards (away from) the radars. The SuperDARN field-of-view is shown with solid gray lines. Localized transient backscatter regions, named as "backscatter blobs" hereafter, are marked by pink ellipses. We further marked clockwise and counterclockwise convection vortices with red and blue ellipses, respectively. We draw these ellipses subjectively to fit the observations of both magnetometers and $\mathrm{Su}-$ perDARN. Unfortunately, the map potential analysis of Ruohoniemi and Baker (1998) and the merging velocity analysis using twin radars are not available to derive more significant information, due to a lack of extended backscatter regions. These clockwise and counterclockwise vortices are associated with upward and downward field-aligned currents (e.g. Kataoka et al., 2001).

To compare various features simultaneously, the Altitude Adjusted Corrected Geomagnetic (AACGM) coordinate system is used in this study, which is a synthesis of the corrected geomagnetic coordinate system (CGM) and the Polar Anglo-American Conjugate Experiment (PACE) geomag- 

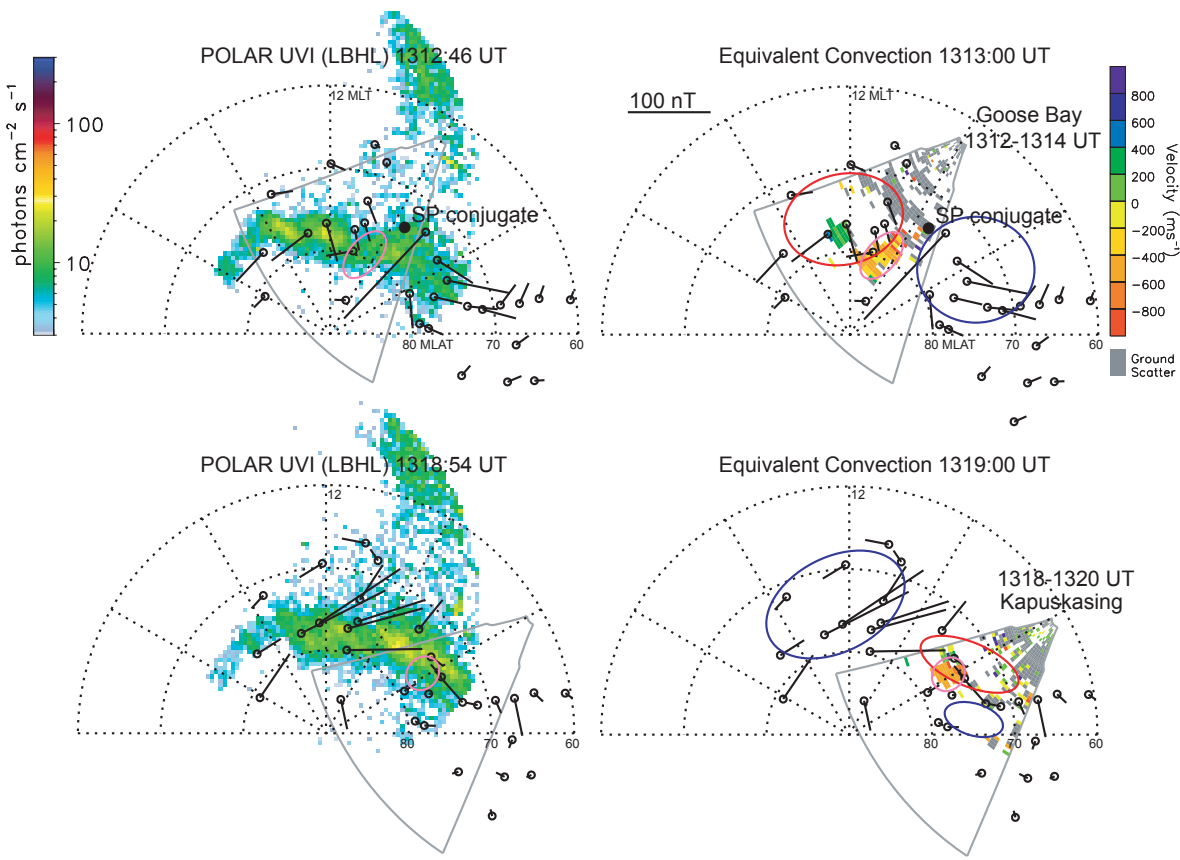

Fig. 1. Equivalent ionospheric convection velocities, POLAR-UVI auroral images, and SuperDARN Doppler velocities in the 24 July 1996 event. Equivalent ionospheric convection velocities derived from magnetometer data are shown by arrows (points away from circles) in the 22 May 1996 event in the polar map. Superposed color maps in the left panels are UV auroral intensity obtained by POLAR-UVI. The color-coded map of Doppler velocity is superposed in the right panels. SuperDARN field-of-view is shown with solid gray line. Red and blue ellipses indicate the subjective position of the clockwise and counterclockwise vortices, respectively. The cells of the "blob" structure are enclosed by pink ellipses. Conjugate points of the South Pole Station in Antarctica are indicated as the black circle with "SP conjugate".
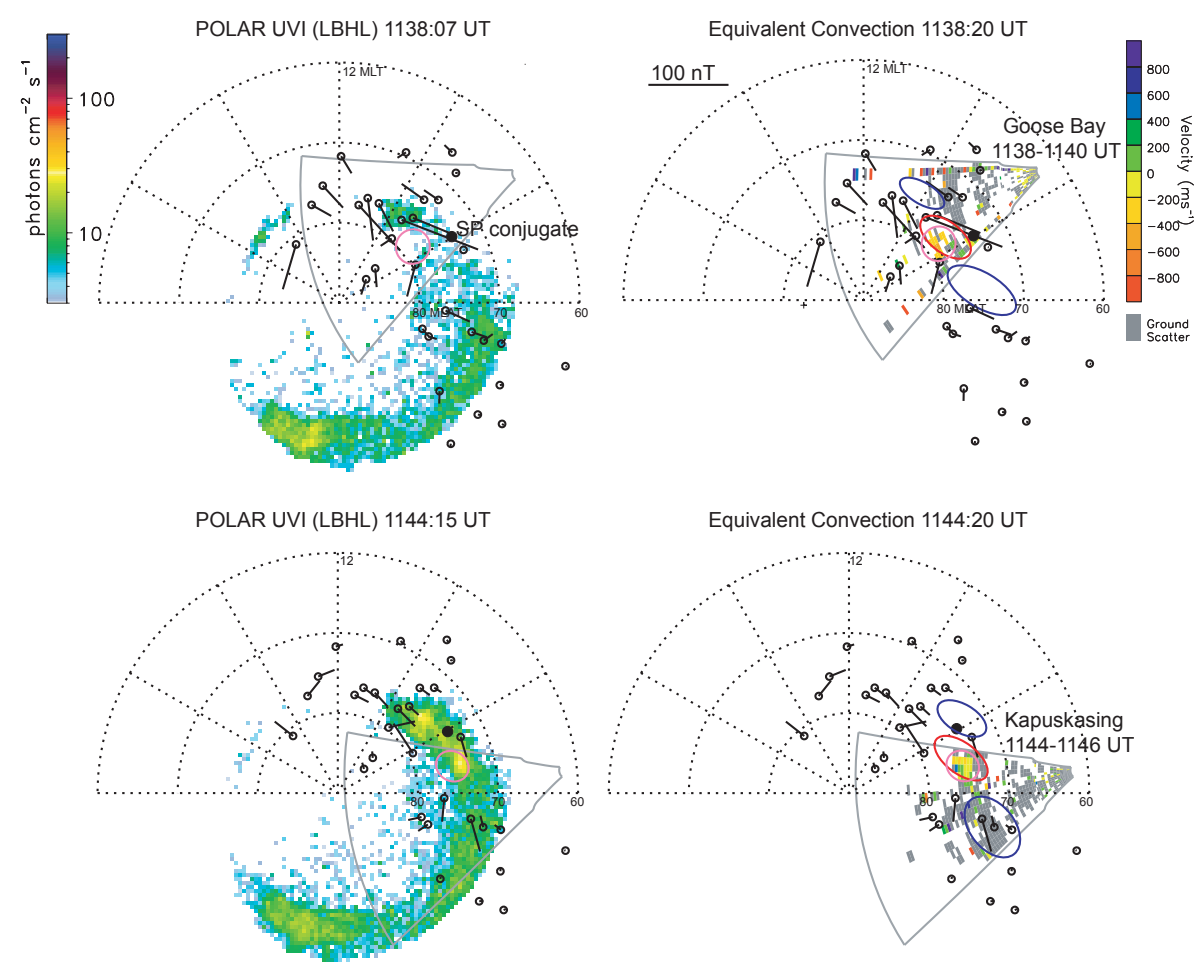

Fig. 2. Equivalent ionospheric convection velocities, POLAR-UVI auroral images, and SuperDARN Doppler velocities in the 24 July 1996 event. The format is the same as Fig. 1. 
Table 1. Geographic and geomagnetic coordinates of magnetometer stations

\begin{tabular}{|c|c|c|c|c|c|c|}
\hline Code & Stations & GLAT & GLON & MLAT & MLON & UT-MLT \\
\hline \multicolumn{7}{|c|}{ CANOPUS } \\
\hline SIM & Fort Simpson & 61.8 & 238.8 & 67.6 & 291.7 & 09:04 \\
\hline $\mathrm{CON}$ & Contwoyto Lake & 65.8 & 248.8 & 73.4 & 301.7 & $08: 23$ \\
\hline SMI & Fort Smith & 60.0 & 248.1 & 67.8 & 304.5 & $08: 13$ \\
\hline MCM & Fort Mcmurray & 56.7 & 248.8 & 64.7 & 307.1 & 08:04 \\
\hline RAB & Rabbit Lake & 58.2 & 256.3 & 67.5 & 317.0 & $07: 27$ \\
\hline TAL & Taloyoak & 69.5 & 266.5 & 79.2 & 328.1 & $06: 47$ \\
\hline RAN & Rankin Inlet & 62.8 & 267.9 & 73.1 & 334.1 & $06: 27$ \\
\hline ESK & Eskimo Point & 61.1 & 266.0 & 71.4 & 331.2 & $06: 37$ \\
\hline $\mathrm{CHU}$ & Fort Churchill & 58.8 & 265.9 & 69.2 & 331.7 & $06: 35$ \\
\hline GIL & Gillam & 56.4 & 265.4 & 66.9 & 331.3 & $06: 37$ \\
\hline ISL & Island Lake & 53.9 & 265.3 & 64.5 & 331.7 & $06: 35$ \\
\hline PIN & Pinawa & 50.2 & 264.0 & 60.7 & 330.2 & $06: 41$ \\
\hline \multicolumn{7}{|c|}{ MACCS } \\
\hline IG & Igloolik & 69.3 & 278.2 & 79.3 & 352.4 & $05: 25$ \\
\hline $\mathrm{GH}$ & Gjoa Haven & 68.6 & 264.1 & 78.1 & 324.3 & 07:00 \\
\hline $\mathrm{RB}$ & Repulse Bay & 66.5 & 273.8 & 76.8 & 343.9 & $05: 54$ \\
\hline $\mathrm{CH}$ & Coral Harbour & 64.1 & 276.8 & 74.5 & 349.8 & $05: 34$ \\
\hline $\mathrm{CD}$ & Cape Dorset & 64.2 & 283.4 & 74.4 & 1.5 & $04: 54$ \\
\hline IQ & Iqaluit & 63.8 & 291.5 & 73.2 & 15.0 & 04:06 \\
\hline \multicolumn{7}{|c|}{ Greenland } \\
\hline THL & Qaanaaq & 77.5 & 290.8 & 85.5 & 34.1 & $02: 52$ \\
\hline SVS & Savissivik & 76.0 & 294.9 & 83.8 & 36.3 & $02: 42$ \\
\hline UPN & Upernavik & 72.8 & 303.9 & 79.6 & 42.3 & $02: 15$ \\
\hline UMQ & Ummannaq & 70.7 & 307.9 & 77.1 & 44.2 & $02: 06$ \\
\hline GDH & Qeqertarsuaq & 69.3 & 306.5 & 76.0 & 40.5 & $02: 22$ \\
\hline STF & Kangerlussuaq & 67.0 & 309.3 & 73.3 & 41.8 & $02: 16$ \\
\hline SKT & Maniitsoq & 65.4 & 307.1 & 72.2 & 38.0 & $02: 33$ \\
\hline FHB & Paamiut & 62.0 & 310.3 & 68.2 & 39.7 & $02: 25$ \\
\hline NAQ & Narsarsuaq & 61.2 & 314.6 & 66.5 & 43.9 & 02:05 \\
\hline $\mathrm{MCN}$ & MAGIC-1 North & 73.9 & 322.4 & 77.5 & 65.7 & $00: 22$ \\
\hline MCG & MAGIC-1 GISP & 72.6 & 321.6 & 76.4 & 62.3 & 00:39 \\
\hline $\mathrm{MCW}$ & MAGIC-1 West & 72.0 & 317.4 & 76.6 & 57.1 & 01:04 \\
\hline NRD & Nord & 81.6 & 343.3 & 80.9 & 106.5 & $21: 13$ \\
\hline DMH & Danmarkshavn & 76.8 & 341.4 & 77.3 & 87.6 & $22: 35$ \\
\hline DNB & Daneborg & 74.3 & 339.8 & 75.2 & 80.8 & 23:06 \\
\hline $\mathrm{SCO}$ & Ittoqqortoormiit & 70.5 & 338.0 & 71.7 & 73.5 & $23: 41$ \\
\hline AMK & Tasiilaq & 65.6 & 322.4 & 69.4 & 54.8 & $01: 14$ \\
\hline \multicolumn{7}{|c|}{ Southern Hemisphere } \\
\hline SP & South Pole & -90.0 & 0.0 & -73.9 & 18.9 & $03: 35$ \\
\hline
\end{tabular}

netic coordinate system (Baker and Wing, 1989). Magnetic local time (MLT) and magnetic latitude in AACGM coordinate system (MLAT) are used to describe the position of the longitudinal and latitudinal direction, respectively. The assumed altitudes are 100, 120, and $400 \mathrm{~km}$ for equivalent convection, POLAR-UVI, and SuperDARN, respectively. The UVI instrument has a wobble and this affects the resolution of the image in the directions of the wobble (roughly 10 pixels). In the 22 May 1996 images, the wobble is roughly in the 15 MLT-3 MLT direction. In the 24 July 1996 images, the wobble is roughly in the 11 MLT-23 MLT direction. Note that the wobble effect does not affect our results and discussions.

It is found that the TCVs are accompanied by localized
HF radar backscatter blobs in the sunlit Northern Hemisphere. The backscatter blobs convected along with the tailward bulk motion of TCVs across the three fields-of-view of HF radars for ten minutes. At 13:12-13:14 UT on 22 May 1996, the backscatter blob first appeared in the 10-12 MLT and 75-85 MLAT sector in the field-of-view of the Goose Bay radar, as shown in the top panels of Fig. 1. At 13:1813:20 UT, the backscatter blob reached to the 7-9 MLT and 74-77 MLAT sector in the field-of-view of the Kapuskasing radar, as shown in the bottom panels of Fig. 1. At 11:3811:40 UT on 24 July 1996, transient irregularities appeared first in the 7-9 MLT and 75-80 MLAT sector in the fieldof-view of the Goose Bay radar, as shown in the top panels of Fig. 2. At 11:44-11:46UT, the backscatter blob reached 
(a) $96143 \quad 1312-1322$ UT

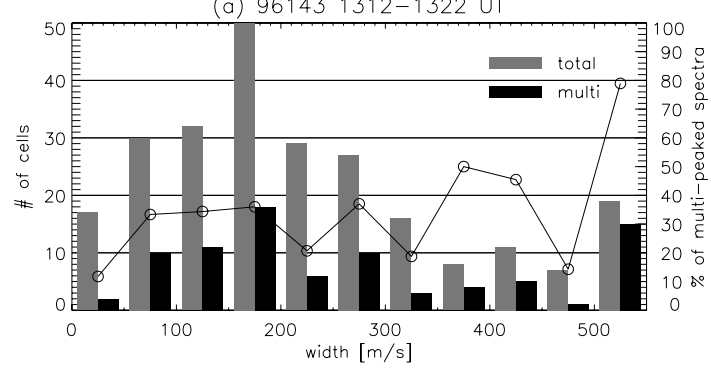

(c) $961431312-1322$ UT

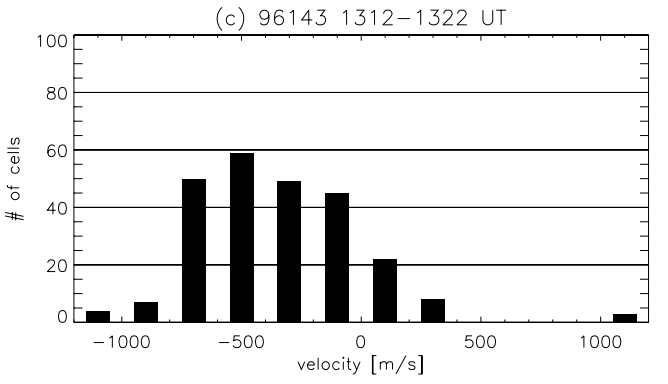

(e) $961431312-1322$ UT

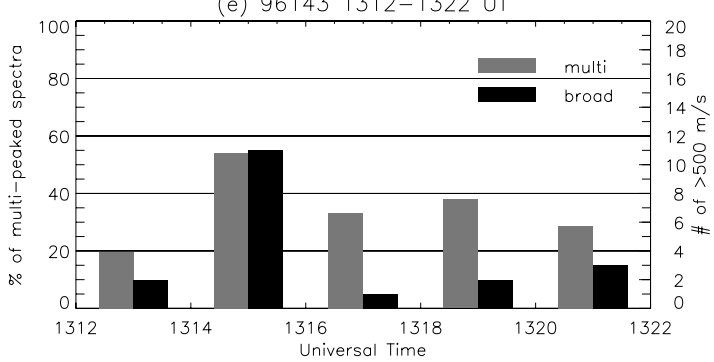

(b) $96206 \quad 1136-1154$ UT
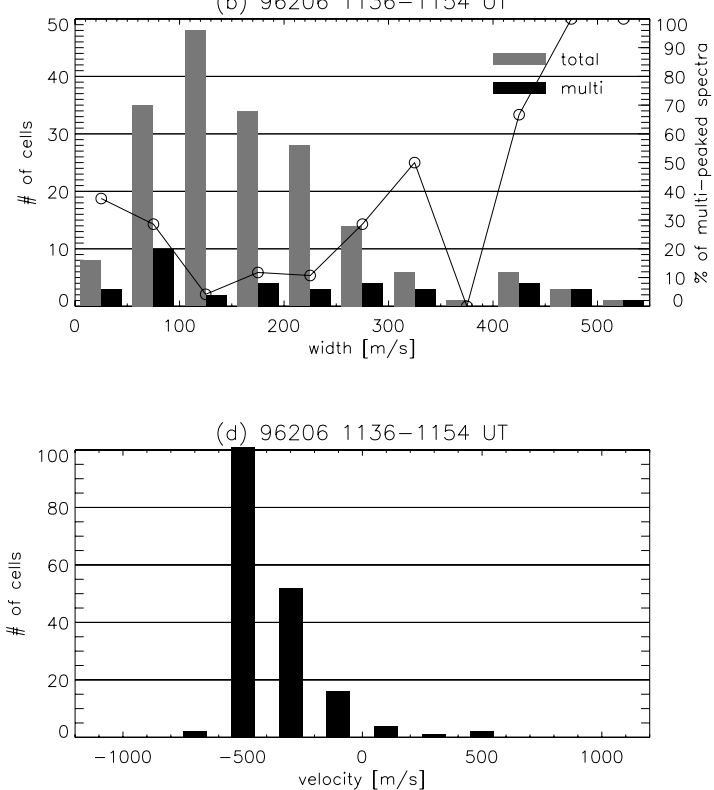

(f) $96206 \quad 1136-1154$ UT

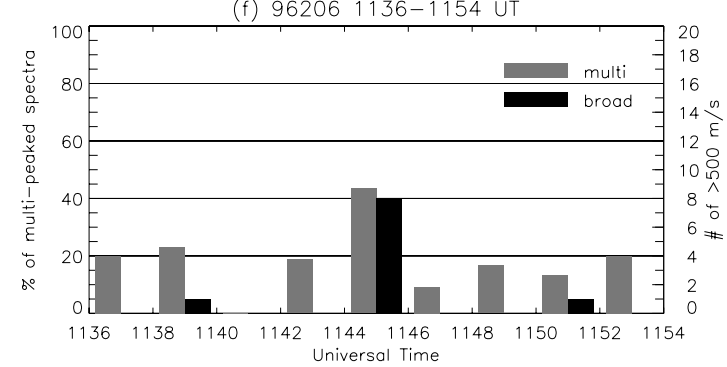

Fig. 3. Histograms of the number of beam-range cells for spectral width (a, b), Doppler line-of-sight velocity within the TCV-related backscatter region (c, d), and multi-peaked spectral events and extremely broad spectral width events (e, f). Percentages of the multi-peaked spectra are superposed with solid lines and circles in the top panels. Sample duration is 13:12-13:22 UT for the 22 May event, and 11:3611:54 UT for the 24 July event, respectively.

to the 5-7 MLT and 74-77 MLAT sector in the field-of-view of the Kapuskasing radar as shown in the bottom panels of Fig. 2. After these periods, the backscatter blobs decayed in the field-of-view of the Saskatoon radar (not shown). These backscatter blobs are located near the leading edge of the upward field-aligned current.

Transient UV auroral enhancements appeared related to the passage of the TCV current system in both events. In the 22 May event, transient UV auroral enhancements appeared around noon at 13:12:46 UT and moved westward (to the 810 MLT sector) in the next frame at 13:18:54 UT (Fig. 1). In the 24 July event, transient UV auroral enhancements appeared around the 10MLT meridian at 11:38:07 UT and moved westward to the 7-10 MLT sector in the next frame at 11:44:15 UT (Fig. 2). It is clearly shown in Figs. 1 and 2 that auroral enhancements are relatively strong in the vortex connected to the upward field-aligned current. The backscatter blobs overlapped the poleward and westward side of these transient aurora, as shown by pink ellipses in Figs. 1 and 2.

\section{Spectral characteristics}

We have investigated the spectral characteristics of the backscatter blobs associated with the TCVs. As shown in Fig. 3, we have constructed the histograms of the number of radar beam-range cells for the ranges of Doppler line-ofsight velocities and spectral widths within each TCV transient backscatter blob. The time interval of the histograms is 13:12-13:22 UT for the 22 May event, and 11:36-11:54 UT for the 24 July event. Since the backscatter blobs traveled across the three fields-of-view of HF radars during both intervals, counts are added for all three radars. We used Doppler line-of-sight velocities and spectral widths derived by the FITACF algorithm (Villain et al., 1987; Baker et al., 1988).

As shown in Figs. 3a and b, the Doppler spectral width of the backscatter is mostly within $50-300 \mathrm{~m} / \mathrm{s}$, but sometimes it is over $400 \mathrm{~m} / \mathrm{s}$. We have checked the spectral forms of these backscatters during the TCV time interval. Although single-peaked spectra are dominate, multi-peaked spectra are found occasionally. We define the "multi-peaked spectrum" 
as a spectrum that is composed of two (more than two in most cases) distinct peaks clearly separated from each other. Percentages of the multi-peaked spectra are superposed with open circles connected with solid lines in the top panels. Note that the percentage of the multi-peaked spectral occurrence is significantly enhanced up to $80-100 \%$ in the period of extremely broad $(>400 \mathrm{~m} / \mathrm{s})$ spectral widths. Figures $3 \mathrm{c}$ and $\mathrm{d}$ show that line-of-sight velocities are almost unidirectional, mostly distributed around 400-600 m/s, with flow directions away from the radar for this period. Figures $3 \mathrm{e}$ and $f$ show the time evolution of multi-peaked spectra and extremely broad spectral widths. These multi-peaked spectra and extremely broad spectral widths are found to be observed for the single scan periods of 13:14-13:16 UT for the 22 May event and 11:44-11:46 UT for the 24 July event.

Shown in the left panels of Figs. $4 a$ and $b$ are selfnormalized Doppler spectra from the representative radar cells of extremely broad spectral widths during the scan periods of 13:14-13:16 UT for 22 May event and 11:4411:46 UT for 24 July event, respectively. Spectral widths derived by the FITACF analysis are also shown in individual Doppler spectra, with a color scale displayed on the right. In the right panels of Figs. $4 a$ and $b$, the backscatter power and spectral width are color-coded in the polar map for the same scan period. The field-of-view of the radar is shown by solid lines. We found from Figs. $4 \mathrm{a}$ and $\mathrm{b}$ that most of these spectral forms are deformed from the simple Gaussian or Lorenzian curve and have several peaks, particularly in higher latitudes, although single-peaked spectra similar to the simple Gaussian or Lorenzian curve are rather common in other scan times. The amplitudes of these multi-peaked spectra are large compared with those of noise spectra. These multi-peaked spectra could cause the FITACF algorithm to overestimate the values the of spectral width (see Andre et al., 1999).

\section{Discussion}

5.1 Generation mechanism of the TCV-related backscatter blobs

The plasma instability is a key process in producing ionospheric plasma irregularities necessary for HF radar backscatter. Here, we investigate what kind of instability process can occur inside the transient backscatter blobs. First, let us discuss the unidirectional line-of-sight Doppler velocity distribution in Fig. 3, which may suggest that the plasma flow direction controls the growth of the instability. Since the gradient drift instability (GDI) occurs when the direction of the plasma drift is parallel to the background density gradient, this instability would be the most plausible candidate for the generation of irregularities inside the blobs. Note that plasma velocity inside the blob is predominantly away from the radar. Combining two-dimensional patterns of convection velocities obtained by magnetometers, the velocity vectors should be directed poleward and/or eastward. In that case, the background density gradient vector must be directed poleward and/or eastward. According to the IRI-90 model (Bilitza, 1990), the background density gradient produced by a sunlit effect is directed nearly eastward (with an increase of $\sim 0.2 \times 10^{5}$ per 2.0 MLT at $300 \mathrm{~km}$ altitudes) in the high-latitude prenoon sector for both events. This background density gradient alone is too small to produce GDI, as discussed below. A plausible candidate to produce localized and strong density gradient is the F-region density wake structure of the TCV. The TCV wake can produce a strong poleward density gradient in the high-latitude portion of the TCV current system. From an ionospheric simulation, Schunk et al. (1994) showed that localized temperature enhancement and electron density depression occur in the TCV wake structure when the maximum convection electric field is $100 \mathrm{mV} / \mathrm{m}$, corresponding to a drift velocity of $2 \mathrm{~km} / \mathrm{s}$. Valladares et al. (1999) showed the signature of density depression by a factor of two at F-region altitudes during a TCV event with magnetic perturbations larger than $100 \mathrm{nT}$. Both authors indicated that the $\mathrm{O}^{+}$recombination due to strong electric field causes density depression via enhanced frictional heating (for details in the role of frictional heating, see Schunk et al., 1975).

Second, we have estimated how large an electric field or plasma flow speed is needed for a significant density depression in the TCV wake structure via $\mathrm{O}^{+}$recombination with $\mathrm{N}_{2}$. We use the reaction rate of $\mathrm{O}^{+}$with $\mathrm{N}_{2}$ given by St.Maurice and Laneville (1998) as a function of an effective temperature $T_{\text {eff }}$ for the reaction below

$\mathrm{O}^{+}+\mathrm{N}_{2} \stackrel{k 1}{\longrightarrow} \mathrm{NO}^{+}+\mathrm{O}$.

The value of $T_{\text {eff }}$ is given by the expression,

$T_{e f f}=\frac{m_{n}}{m_{i}+m_{n}}\left(\frac{m_{i} U^{2}}{3 k_{B}}+T_{i}-T_{n}\right)+T_{n}$,

where $m_{n}$ and $m_{i}$ are the masses of the neutral and ion reactants, respectively, $k_{B}$ is the Boltzmann constant, $T_{i}$ and $T_{n}$ are the ion and neutral temperatures, respectively, and $U$ is the magnitude of the relative velocity between ion and neutral motions. The ion temperature due to ion frictional heating above the $200 \mathrm{~km}$ altitude is given by (e.g. Schunk et al., 1975)

$T_{i}=T_{n}+\frac{m_{a} U^{2}}{3 k_{B}}$,

where $m_{a}$ is the mass of the ambient gas. If we assume an ambient gas consisting of atomic oxygen, the effective temperature for $\mathrm{O}^{+}$recombination with $\mathrm{N}_{2}$ is given by $T_{\text {eff }}=$ $T_{n}+8.2 \times 10^{4} U^{2}$. Now we assume that any production and transport terms in the continuity equation remain in a steady state, and that the loss term alone has an effect on the density depression because of its time constant. Then we obtain an approximate relation of the density depression rate $\alpha$ as

$\alpha=\frac{\delta\left[\mathrm{O}^{+}\right]}{\left[\mathrm{O}^{+}\right]}=\left(k 1\left(T_{e f f}\right)-k 1\left(T_{n}\right)\right)\left[\mathrm{N}_{2}\right] \delta t$, 
(a) May 22, 1996 Goose Bay 1314-1316 UT
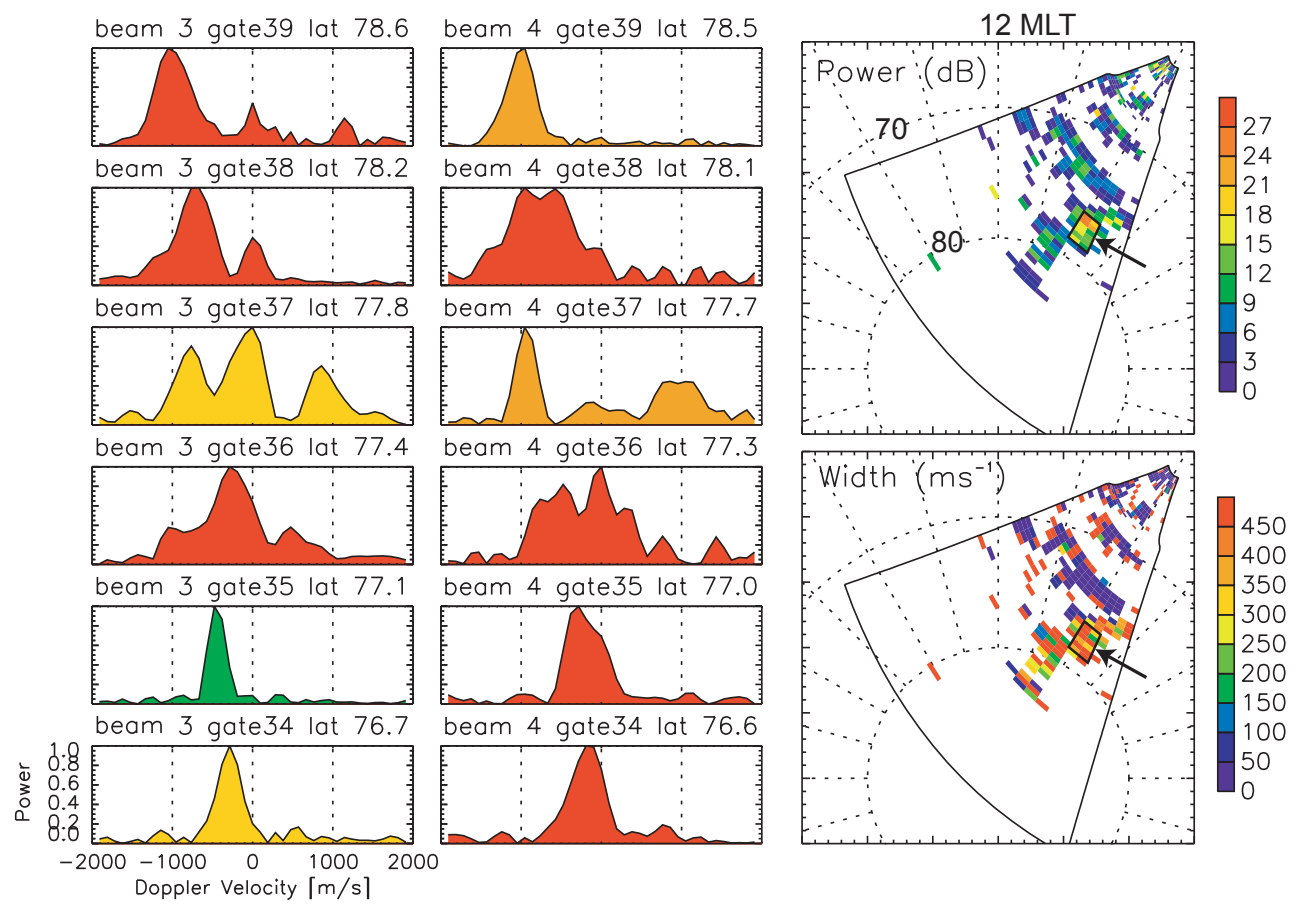

(b) July 24, 1996 Kapuskasing 1144-1146 UT
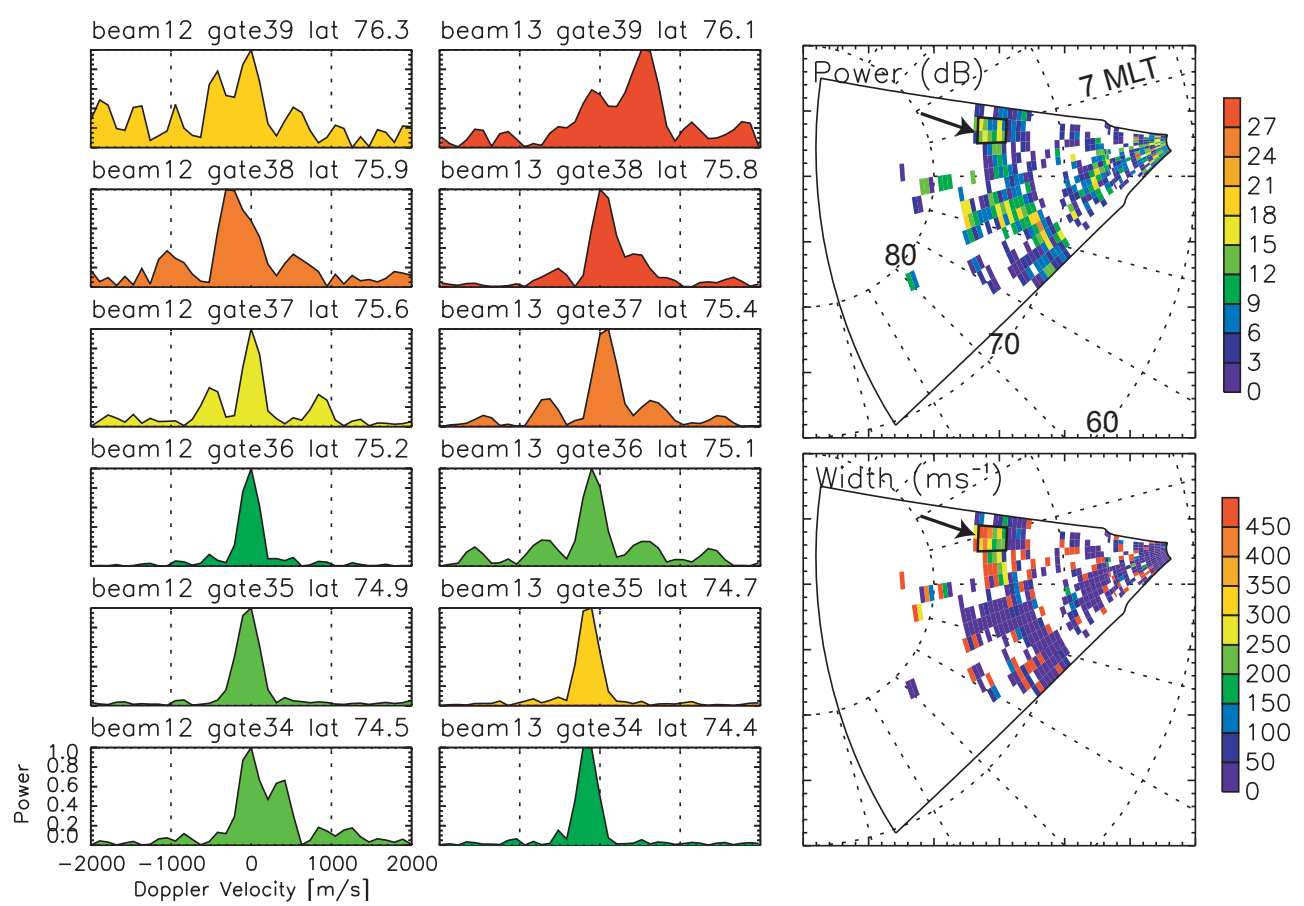

Fig. 4. Self-normalized Doppler spectra from the representative radar cells of extremely broad spectral widths during the periods of (a) 13:14-13:16 UT in the 22 May event, and (b) 11:44-11:46 UT in the 24 July event, respectively. Spectral widths derived by the FITACF analysis are also shown in individual Doppler spectra with a color scale displayed on the right. Right panels show the color-coded backscatter power and spectral width in the polar map for the same scan period. Selected cells are arrowed and enclosed by solid squares. 


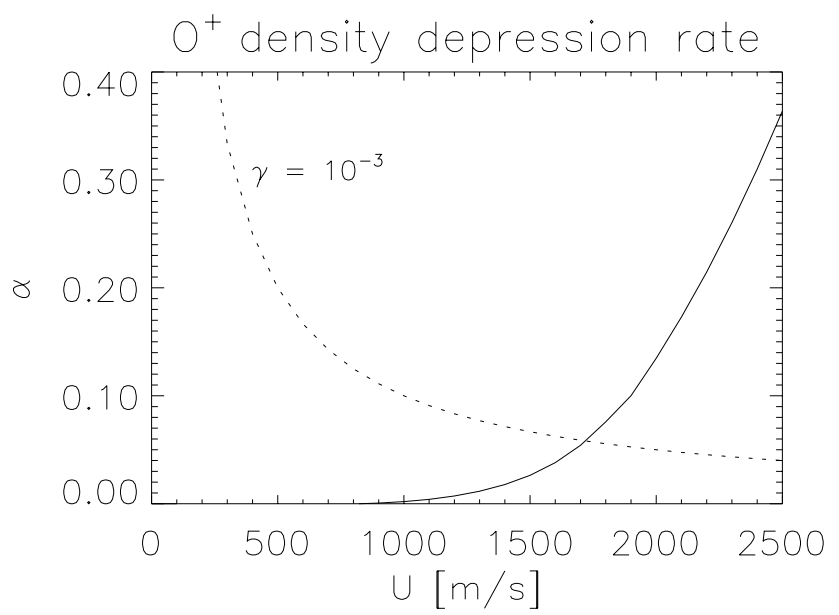

Fig. 5. Density depression rate (solid line) and the threshold of the GDI growth rate (dotted line) as a function of the plasma flow velocity.

where $\left[\mathrm{N}_{2}\right],\left[\mathrm{O}^{+}\right]$, and $\delta\left[\mathrm{O}^{+}\right]$are the number density of nitrogen, oxygen ion, and its fluctuation during the time of $\delta t$. We choose $\delta t=10^{2}$ as a typical time for TCV transients.

The one-dimensional GDI growth rate is given by Linson and Workman (1970) as

$\gamma_{\mathrm{GDI}}=\frac{U}{L}$,

where $L$ is the scale length of the plasma density gradient, i.e. $L=n /|\nabla n|$. We expect that the GDI growth rate would be huge because the backscatter blobs appeared with the TCV timing in both events. Such a huge growth rate allows us to use an instantaneous GDI growth rate for correct estimation; nevertheless, the history of plasma along the streamline should be considered in general (Sojka et al., 2000). In order to accomplish GDI during TCV duration, the growth rate would be larger than at least $10^{-3} \mathrm{~s}^{-1}$. If we assume the created density slope has a scale of $10^{2} \mathrm{~km}, U \alpha$ should be larger than $10^{-1}$.

We plot the density depression rate $\alpha$ as a function of $U$ with a solid curve in Fig. 5. We use typical values from the MSISE-90 model (Hedin, 1991) under sunlit highlatitude conditions at $300 \mathrm{~km}$ altitude $\left(\left[\mathrm{N}_{2}\right]=10^{8} \mathrm{~cm}^{-3}\right.$ and $T_{n}=800 \mathrm{~K}$ ). A dotted line shows the threshold for the GDI to occur as explained above. It is found that the relative velocity between ion and neutral species, $U$, needs at least $1.7 \mathrm{~km} / \mathrm{s}$ for producing GDI at this condition. Also, an effect on density depression due to convection flow less than $1.0 \mathrm{~km} / \mathrm{s}$ is negligible $(<1 \%)$. In Fig. 3, we showed that the Doppler velocity is typically distributed in the range 400 $600 \mathrm{~m} / \mathrm{s}$. It is clear from Fig. 3 that the observed flow speed is too slow to meet the criteria. It would be impossible for this one-dimensional GDI story alone to accomplish the formation of the significant TCV wake and to make the irregularities.

Now we turn to discussing other possibilities. The present study showed that the backscatter blob is located in the pole- ward and westward part of the transient UV aurora. It is also shown in Figs. 1 and 2 that electron precipitation is relatively strong in the upward field-aligned current vortex. The localized upward current distribution around the blob may have the possibility of making the density irregularities. The current convective instability (CCI), that is the threedimensional version of GDI caused by the upward fieldaligned current (Ossakow and Chaturvedi, 1979), could elevate the growth rate significantly, compared with the one derived from the one-dimensional GDI story described above. Note that CCI occurs even under the stable condition for GDI. We further speculate that the growth rate could be rapidly enhanced via some nonlinear processes, such as a production of density irregularities due to structured electron precipitation themselves (Kelley et al., 1982), and a formation of strong background density gradient in the F-region due to transient soft-electron precipitation within the TCV current system. The observed unidirectional Doppler velocities are also explained because the motion of the irregularity region is fixed under a portion of the TCV current system, where the growth rate is maximized. From the discussion above, we conclude that the transient backscatter blob would not be produced by one-dimensional GDI process but by the three-dimensional GDI process through the nonlinear rapid evolution of instabilities in the upward field-aligned current region.

\subsection{Spectral characteristics within the blob}

We discuss the causes of multi-peaked spectral forms and large increases in spectral widths. The Doppler spectral width is a measure of the variation of electric field in both the spatial domain corresponding to the radar sampling cell (typically $45 \mathrm{~km}$ by $100 \mathrm{~km}$ in dimension) and the time domain corresponding to the radar integration time of $7 \mathrm{~s}$. A large increase in the spectral width indicates that the electric field has varied rapidly in one or both of these two domains.

A possible source for making the extreme broad spectral width is Pc1-2 bursts. Recent studies (see Sato et al., 1999 and references therein) showed that Pc1 bursts are closely correlated with TCVs. Kataoka et al. (2001) also mentioned the occurrence of the pronounced increase in Doppler spectral width as seen by SuperDARN when the TCV passed through the irregularity region. Andre et al. $(1999,2000 \mathrm{~b})$ have evaluated the impact of time-varying electric field on the spectral width as seen by SuperDARN. Even though their story can explain how Pc1-2 bursts make transient broad spectral widths and multi-peaked spectra, there has been no report so far on the simultaneous occurrences of the Pc1-2 burst and the backscatter with broad spectral widths. In this scope, we have checked search-coil magnetometer data for both events.

Pc1-2 bursts were observed at the South Pole Station in Antarctica, the conjugate point of the backscatter region in the Northern Hemisphere (see Figs. 1 and 2). Figures 6a and $\mathrm{b}$ show the magnetometer data observed in the 22 May event and the 24 July event, respectively. The top panel shows the 
(a)

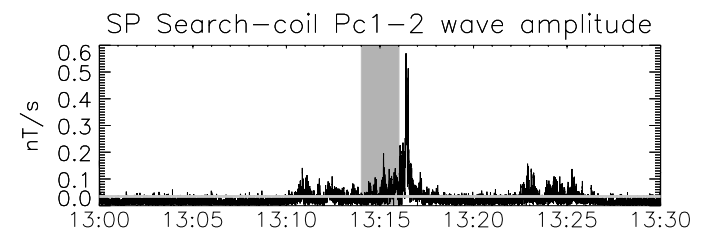

SP Fluxgate $H$ (north) and IQ Fluxgate $H$ (north)

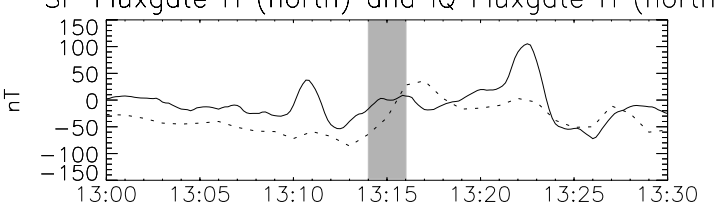

SP Fluxgate $-D$ (west) and IQ Fluxgate D(east)

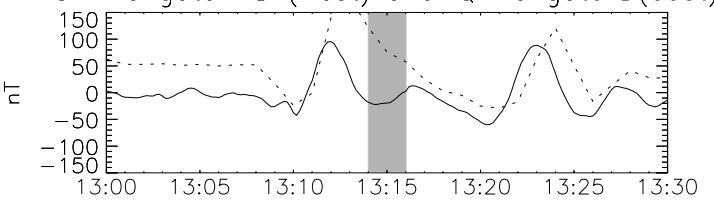

SP Fluxgate Z (up) and IQ Fluxgate Z (down)

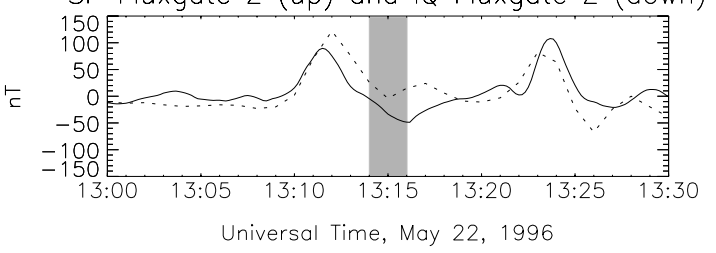

(b)

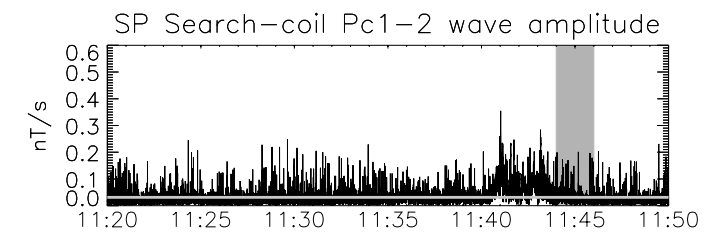

SP Fluxgate $H$ (north) and IQ Fluxgate $H$ (north)
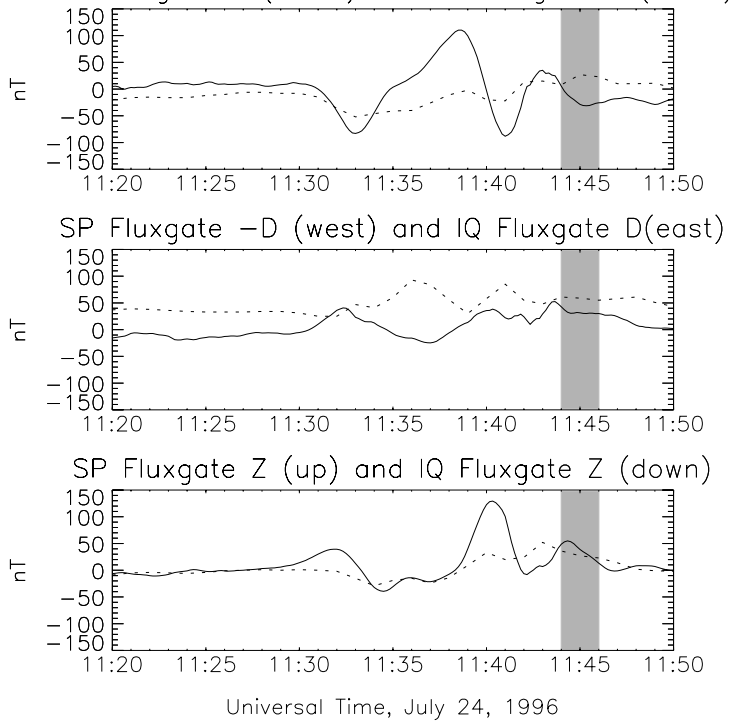

Fig. 6. Pc1-2 activities and magnetic impulse events observed by conjugate magnetometers. The top panels show the amplitude of the band-pass filtered time series in the Pc1-2 range $(0.1-5.0 \mathrm{~Hz})$ using $10 \mathrm{~Hz}$ sampling search-coil magnetometer data at the South Pole (SP) in Antarctica in a (a) 22 May event and (b) 24 July event, respectively. The standard deviation of $1 \sigma$ is plotted with gray horizontal lines. The bottom three panels show the three components of fluxgate magnetometer data at SP. Conjugate magnetometer data at Iqaluit (IQ) are also plotted with dotted lines. Shaded time intervals correspond to the observation period of extremely broad spectra.

amplitude of the band-pass filtered time series in the Pc1-2 range $(0.1-5.0 \mathrm{~Hz})$ using $10-\mathrm{Hz}$ sampling search-coil magnetometer data from the South Pole Station. The standard deviation of $1 \sigma$ is plotted with a gray horizontal line for the reference of amplitude fluctuations. The bottom three panels show the three components of fluxgate magnetometer data from the South Pole Station, and the conjugate data from Iqaluit are also plotted with dotted lines to show that similar vortices passed in both hemispheres, in terms of "magnetic impulse events" (Lanzerotti et al., 1986, 1987). It is noticed that Pc1-2 activity is enhanced during the TCV passage in the intervals of 13:10-13:18 UT in Fig. 6a and 11:4011:46 UT in Fig. 6b. This observational result supports the story of Andre et al. (1999, 2000b). Note that the most prominent enhancements of Pc1-2 bursts at 13:16-13:17 UT in Fig. 6a and at 11:41 and 11:43 UT in Fig. 6b do not directly correspond to the occurrences of extremely broad spectral widths. This result may suggest that the backscatter regions were located at a few hundreds of km away from the South Pole conjugate point for both events.

It is interesting to note here that the distribution profiles of spectral width in Figs. 3a and $b$ have some similarities to the histograms obtained in the low-latitude boundary layer re- gion by Baker et al. (1995). Andre et al. (2000a) also showed from a simulation study that the spectral width in the velocity gradient region is enhanced as large as $\sim 250 \mathrm{~m} / \mathrm{s}$. Combining the discussion above, we conclude that the distributions of spectral width given in Figs. 3a and b, would be produced by two sources. One is the velocity gradient structure of vortices themselves, which produces gradual background distribution from 50 to $300 \mathrm{~m} / \mathrm{s}$. The other is the time-varying electric field, which enhances the spectral width more than $400 \mathrm{~m} / \mathrm{s}$ when Pc1-2 burst exists.

\section{Summary and conclusion}

The processes of transient production of F-region plasma irregularities associated with two TCV events were investigated with the advantage of a horizontally wide coverage of SuperDARN combined with ground magnetometer networks and POLAR UVI. We found the relationship between occurrences of HF backscatter with extremely broad spectral widths as seen by SuperDARN and TCV events with Pc1-2 bursts.

It is also found that TCV-associated HF backscatter arises in localized blobs with hundred-kilometer extent. These 
blobs traveled following the tailward bulk motion of the TCVs. The flows in the blob region showed unidirectional Doppler velocities away from the radar, mostly distributed in the range of $400-600 \mathrm{~m} / \mathrm{s}$. These unidirectional velocities correspond to the poleward and/or eastward convective flow near the leading edge of the upward fieldaligned current. The backscatter blobs overlapped the poleward and westward side of the TCV-related transient aurora. The transient backscatter blob would be produced by the three-dimensional gradient drift instabilities in the threedimensional current system of the TCV via some nonlinear rapid evolutions of irregularities under the upward fieldaligned current region.

The spectral width of the backscatter blob is typically distributed from 50 to $300 \mathrm{~m} / \mathrm{s}$, but sometimes it is over $400 \mathrm{~m} / \mathrm{s}$. We interpreted the temporal broad spectra over $400 \mathrm{~m} / \mathrm{s}$ as being produced by the Pc1-2 burst, and the gradual background distribution from 50 to $300 \mathrm{~m} / \mathrm{s}$ as being produced by the velocity gradient structure of the vortices themselves.

Acknowledgements. We appreciate helpful discussions with $\mathrm{T}$. Ogawa. We express our sincere thanks to all members of the SuperDARN radar, and geomagnetic field observation network teams: the Greenland chain, CANOPUS, and MACCS. We thank the PIs of Goose Bay, Kapuskasing (R. Greenwald) and Saskatoon (G. Sofko) radars. The Goose Bay and Kapuskasing radars are operated under support from NSF grant ATM-9812078 and NASA grant NAG58361. Operation of the Saskatoon radar is supported by an NSERC CSP grant for the "The Canadian Component of SuperDARN". We appreciate the assistance of J. Watermann with handling the data from the Greenland magnetometer chain operated by the Danish Meteorological Institute. The Magnetometer Array on the Greenland Ice Cap (MAGIC) was established and is operated by SPRL, University of Michigan, with support from the National Science Foundation. Data for these events were kindly provided by the MAGIC-PI, C.R. Clauer. Also, thanks are extended to T. Hughes for magnetometer data from CANOPUS. The CANOPUS instrument array was constructed, maintained, and operated by the Canadian Space Agency for the Canadian scientific community. We also thank M. Engebretson for use of magnetometer data from MACCS and the search-coil magnetometer data at South Pole Station. We thank L. J. Lanzerotti for the fluxgate magnetometer data at South Pole Station. We thank G. Parks, the PI of POLAR UVI. This research is supported by the Grant-in Aid for Scientific Research (A: 11304029) from Japan Society for the Promotion of Science (JSPS).

Topical Editor M. Lester thanks C. R. Clauer and another referee for their help in evaluating this paper.

\section{References}

Andre, R., Pinnock, M., and odger, A. S.: On the SuperDARN autocorrelation function observed in the ionospheric cusp, Geophys. Res. Lett., 22, 3353, 1999.

Andre, R., Pinnock, M., Villain, J.-P., and Hanuise, C.: On the factor conditioning the Doppler spectral width determined from SuperDARN HF radars, International Journal of Geomagnetism and Aeronomy, 2, 77, 2000a.

Andre, R., Pinnock, M., and Rodger, A. S.: Identification of the low-altitude cusp by Super Dual Auroral Radar Network radars:
A physical explanation for the empirically derived signature, J. Geophys. Res., 105, 27 081, 2000 b.

Baker, K. B., Greenwald, R. A., Villain, J. P., and Wind, S.: Spectral characteristics of high-frequency (HF) backscatter from high latitude ionospheric irregularities: Preliminary analysis of statistical properties, Interim Rep., RADC-TR-87-284, Rome Air Dev. Cent., Griffis Air Force Base, New York, 1988.

Baker, K. B. and Wing, S.: A new magnetic coordinate system for conjugate studies at high-latitudes, J. Geophys. Res. 94, 9139, 1989.

Baker, K. B., Dudeney, J. R., Greenwald, R. A., Pinnock, M., Newell, P. T., Rodger, A. S., Mattin, N., and Meng, C.-I.: HF radar signatures of the cusp and low-latitude boundary layer, J. Geophys. Res., 100, 7671, 1995.

Bilitza, D.: International Reference Ionosphere 1990, NSSDC 9022, Greenbelt, Maryland, 1990.

Chua, D. H.: Ionospheric influence on the global characteristics of electron precipitation during auroral substorms, $\mathrm{Ph}$. D. thesis, University of Washington at Seattle, Seattle, WA, 2002.

Friis-Christensen, E., McHenry, M. A., Clauer, C. R., and Vennerstrom, S.: Ionospheric traveling convection vortices observed near the polar cleft: A triggered response to sudden changes in the solar wind, Geophys. Res. Lett., 15, 253, 1988.

Fukushima, N.: Equivalence in ground geomagnetic effect of Chapman-Vestine's and Birkeland-Alfven's electric current systems for polar magnetic storms, Rep. Ionos. Space. Res. Jpn. 23(3), 219, 1969.

Germany, G. A., Torr, M. R., Torr, D. G., and Richards, P. G.: Use of FUV auroral emissions as diagnostic indicators, J. Geophys. Res., 99, 383, 1994.

Glassmeier, K. H. and Heppner, C.: Traveling convection twin vortices: Anothre case study, global characteristics, and a model, J. Geophys. Res., 97, 3997, 1992.

Greenwald, R. A., Baker, K. B., Hutchines, R. A., and Hanuise, C.: An HF phases-array radar for studying small-scale structure in the high latitude ionosphere, Radio Science, 20, 63, 1985.

Greenwald, R. A., Bristow, W. A., Sofko, G. J., Senior, C., Cerisier, J.-C., and Szabo, A.: Super dual auroral radar network radar imaging of dayside high latitude convection under northward interplanetary magnetic field: Toward resolving the distorted twocell versus multicell controversy, J. Geophys. Res., 100, 19661 , 1995.

Hedin, A. E.: Extension of the MSIS thermospheric model into the middle and lower atmosphere, J. Geophys. Res., 96, 1159-1172, 1991.

Hughes, W. J. and Engebretson, M. J.: MACCS: Magnetometer array for cusp and cleft studies, in: Satellite - Ground Based Coordination Sourcebook, (Eds) Lockwood, M. et al., Eur. Space Agency Spec. Publ., SP-1998, 119, 1997.

Kataoka R., Fukunishi, H., Lanzerotti, L. J., Maclennan, C. G., Frey, H. U., Mende, S. B., Doolittle, J. H., Rosenberg, T. J., and Weatherwax, A. T.: Magnetic Impulse Event: A detailed case study of extended ground and space observations, J. Geophys. Res., 106, 25 873, 2001.

Kataoka, R., Fukunishi, H., Lanzerotti, L. J., Rosenberg, T. J., Weatherwax, A. T., Engebretson, M. J., and Watermann, J.: Traveling convection vortices induced by solar wind tangential discontinuities, J. Geophys. Res., 107, 10.1029/2001JA009102, 2002.

Kelley, M. C., Vickrey, J. F., Carlson, C. W., and Torbert, R.: On the origin and spatial extent of high-latitude F-region irregularities, J. Geophys. Res., 87, 4469, 1982. 
Lanzerotti, L. J., Lee, L. C., Maclennan, C. G., Wolfe, A., and Medford, L. V.: Possible evidence of flux transfer events in the polar ionosphere, Geophys. Res. Lett., 13, 1089, 1986.

Lanzerotti, L. J., Hunsucker, R. D., Rice, D., Lee, L. C., Wolfe, A., Maclennan, C. G., and Medford, L. V.: Ionosphere and groundbased response to field-aligned currents near the magnetospheric cusp regions, J. Geophys. Res., 92, 7739, 1987.

Linson, L. M. and Workman, J. B.: Formation of striation in ionospheric plasma clouds, J. Geophys. Res., 75, 3211, 1970.

Lühr, H., Blawert, W., and Todd, H.: Ionospheric plasma and current patterns of travelling convection vortices: a case study, J. Atmos. Terr. Phys., 55, 1717, 1993.

Lühr, H., Lockwood, M., Sandholt, P. E., Hansen, T. L., and Moretto, T.: Multi-instrument ground-based observations of a travelling convection vortices event, Ann. Geophysicae, 14, 162, 1996.

Lyatsky, W. B., Sofko, G. J., Kustov, A. V., Andre, D., Hughes, W. J., and Murr, D.: Traveling convection vortices as seen by the SuperDARN HF radars, J. Geophys. Res., 104, 2591, 1999.

Milan, S. E., Lester, M., Cowley, S. W. H., Moen, J., Sandholt, P. E., and Owen, C. J.: Meridian-scanning photometer, coherent HF radar, and magnetometer observation of the cusp: a case study, Ann. Geophysicae, 17, 159, 1999.

Ossakow, S. L. and Chaturvedi, P. K.: Current convective instability in the diffuse aurora, Geophys. Res. Lett., 6, 332, 1979.

Rodger, A. S., Mende, S. B., Rosenberg, T. J., and Baker, K. B.: Simultaneous optical and HF radar observations of the ionospheric cusp, Geophys. Res. Lett., 22, 2045, 1995.

Ruohoniemi, J. M. and Baker, K. B.: Large-scale imaging of highlatitude convection with Super Dual Auroral Radar Network HF radar observations, J. Geophys. Res., 103, 20 797-20 811, 1998.

Sato, M., Fukunishi, H., Lanzerotti, L. J., and Maclennan, C. G.: Magnetic impulse events and related Pc1 bursts observed by the Automatic Geophysical Observatories network in Antarctica, J. Geophys. Res., 104, 19971, 1999.

Schunk, R. W., Raitt, W. J., and Banks, P. M.: Effect of electric fields on the daytime high-latitude E- and F-regions, J. Geophys.
Res., 80, 3121, 1975.

Schunk, R. W., Zhu, L., and Sojka, J. I.: Ionospheric response to traveling convection twin vortices, Geophys. Res. Lett., 21, 1759, 1994.

Schunk, R. W., Zhu, L., and Sojka, J. I.: Effect of convection vortices on the ionosphere, Adv. Space Res., 22, 1365, 1998.

Sibeck, D. G., Borodkova, N. L., Schwartz, S. J., et al.: Comprehensive study of the magnetospheric response to a hot flow anomaly, J. Geophys. Res., 104, 4577, 1999.

Sitar, R. J., Baker, J. B., Clauer, C. R., Ridley, A. J., Cumnock, J. A., Papitashvilli, V. O., Spann, J., Brittnacher, M. J., and Parks, G. K.: Multi-instrument analysis of the ionospheric signatures of a hot flow anomaly occurring on 24 July 1996, J. Geophys. Res., 103, $23357,1998$.

Sojka, J. J., Zhu, L., David, M., and Schunk, R. W.: Modeling the evolution of meso-scale ionospheric irregularities at high latitudes, Geophys. Res. Lett., 27, 3595, 2000.

St.-Maurice, J.-P. and Laneville, P. J.: Reaction rate of $\mathrm{O}^{+}$with $\mathrm{O}_{2}$ $\mathrm{N}_{2}$, and NO under highly disturbed auroral conditions, J. Geophys. Res., 103, 17 519, 1998.

Torr, M. R., Torr, D. G., Zukic, M., et al.: A far ultraviolet imager for the international solar-terrestrial physics mission, Space Sci Rev., 71, 329, 1995.

Valladares, C. E., Alcaydé, D., Rodriguez, J. V., Ruohoniemi, J. M., and Van Eyken, A. P.: Observations of plasma density structures in association with the passage of traveling convection vortices and the occurrence of large plasma jets, Ann. Geophysicae, 17, 1020, 1999.

Villain, J.-P., Greenwald, R. A., Baker, K. B., and Ruohoniemi, J. M.: HF radar observations of E-region plasma irregularities produced by oblique electron streaming, J. Geophys. Res., 92, $12327,1987$.

Yeoman, T. K., Lester, M., Cowley, S. W. H., Milan, S. E., Moen, J., and Sandholt, P. E.: Simultaneous observation of the cusp in optical, DMSP and HF radar data, Geophys. Res. Lett., 24, 2251, 1997. 